\title{
Prehospital electrocardiogram shortens ischaemic time in patients with ST-segment elevation myocardial infarction
}

\author{
KS Cheung *, LP Leung, YC Siu, TC Tsang, Matthew SH Tsui, CC Tam, Raymond HW Chan
}

This article was published on 9 Oct 2019 at www.hkmj.org.

\section{A B S T R A C T}

Introduction: Total ischaemic time should be shortened as much as possible in patients with STsegment elevation myocardial infarction (STEMI). This study evaluated whether prehospital 12-lead electrocardiogram (ECG) could shorten system delay in STEMI management.

Methods: From November 2015 to November 2017, 15 ambulances equipped with X Series Monitor/ Defibrillator (Zoll Medical Corporation) were used in the catchment area of Queen Mary Hospital, Hong Kong. Prehospital ECG was performed for patients with chest pain; the data were teletransmitted to attending emergency physicians at the Accident and Emergency Department (AED) for rapid assessment. Data from patients with STEMI who were transported by these 15 ambulances were compared with data from patients with STEMI who were transported by ambulances without prehospital ECG or who used self-arranged transport.

Results: Data were analysed from 197 patients with STEMI. The median patient delay for activation of the emergency response system was 90 minutes; $12 \%$ of patients experienced a delay of $>12$ hours. There was a significant difference in delay between patients transported by ambulance and those who used selfarranged transport $(\mathrm{P}<0.001)$. For system delay, the use of prehospital ECG shortened the median time from ambulance on scene to first ECG $(\mathrm{P}<0.001)$. When performed upon ambulance on scene, prehospital ECG was available 5 minutes earlier than if performed in ambulance compartment before departure. Use of prehospital ECG significantly shortened AED door-to-triage time, AED doorto-first AED ECG time, AED door-to-physician consultation time, and length of stay in the AED ( $\mathrm{P}<0.001$ for all comparisons).

Conclusion: Prehospital ECG shortened ischaemic time prior to hospital admission.

\section{Hong Kong Med J 2019;25:356-62 \\ https://doi.org/10.12809/hkmj197995}

\author{
${ }^{1}$ KS Cheung *, FHKCEM \\ ${ }^{2}$ LP Leung, FHKCEM \\ ${ }^{3}$ YC Siu, FHKCEM \\ ${ }^{1}$ TC Tsang, FHKCEM \\ ${ }^{1}$ MSH Tsui, FRCP (Edin), FHKAM (Emergency Medicine) \\ ${ }^{4}$ CC Tam, FHKCP, FHKAM (Medicine) \\ ${ }^{5}$ RHW Chan, FHKAM (Medicine)
}

\section{Department of Accident and Emergency, Queen Mary Hospital, Pokfulam, Hong Kong \\ 2 Emergency Medicine Unit, Li Ka Shing Faculty of Medicine, The University of Hong Kong, Pokfulam, Hong Kong \\ Fire and Ambulance Services Academy, Hong Kong Fire Services Department, Tseung Kwan O, Hong Kong \\ ${ }^{4}$ Department of Medicine, Queen Mary Hospital, Pokfulam, Hong Kong \\ ${ }^{5}$ Division of Cardiology, Hong Kong Sanatorium \& Hospital, Happy Valley, Hong Kong}

* Corresponding author: cks373@ha.org.hk

New knowledge added by this study

- Patient delay is significantly longer for patients who use self-arranged transport compared with those transported by ambulance.

- System delay-in particular the time from ambulance on scene to first electrocardiogram (ECG) -is significantly shorter with prehospital ECG than without.

Implications for clinical practice or policy

- To minimise ischaemic time, ECG should be performed on scene, rather than in the ambulance compartment whenever feasible.

- This evidence supports a recommendation for the Hong Kong Fire Services Department to purchase prehospital ECG machines for the whole territory in the future.

\section{Introduction}

common atherosclerosis to life-threatening ST-

Approximately 10.6 persons in Hong Kong die of segment elevation myocardial infarction (STEMI). coronary heart diseases each day. ${ }^{1}$ Coronary heart The European Society of Cardiology has divided diseases represent a spectrum of disorders, from the total ischaemic time in patients with STEMI 
into patient and system delays. ${ }^{2}$ System delays are further subdivided into emergency medical system and non-emergency medical system (hospital) delays. Minimising delays of all types would be most beneficial for patient outcome. To the best of our knowledge, there have been no studies of the components of ischaemic time in patients with STEMI in Hong Kong.

The Hong Kong Fire Services Department (HKFSD) serves as the primary emergency ambulance provider in Hong Kong. Ambulance services are activated by the Fire Service Control Centre upon calls to 999; the ambulances are staffed in accordance with protocols approved by the HKFSD Medical Director. ${ }^{3}$ Patients are transported to the nearest public hospital, based on their geographical location. There is no opportunity for patients to choose the destination hospital, and no primary diversions are used for chest pain/STEMI.

To shorten the total ischaemic time in patients with STEMI, the HKFSD and the Department of Accident and Emergency (AED) of Queen Mary Hospital (QMH) jointly launched a pilot project named 'Prehospital Ambulance 12-lead Electrocardiogram for Chest Pain Patients in Hong Kong West Cluster.' Our group previously published an article using data from the first phase of this pilot project (12 November 2015 to 31 December 2016), demonstrating the impact of prehospital 12-lead electrocardiogram (ECG) on door-to-balloon time (D2B) in patients with STEMI who received primary percutaneous coronary intervention (PPCI). ${ }^{3}$ However, the majority of D2B time constituted the post-admission period, whereas myocardial injury likely began with the onset of symptoms before hospital admission. We hypothesised that prehospital ECG would also shorten the ischaemic time before hospital admission, including the first medical contact-to-first ECG time, AED door-to-triage and AED door-to-consultation time, and length of stay in the AED. In the present analysis, pre-admission data from our pilot project were compared with those of patients with STEMI who received the standard management. By assessing the patient flow from the onset of symptoms until admission, patient and system delays could be identified, and potential improvements could be implemented accordingly.

\section{Methods}

This was a retrospective observational study of data from the first and second phases of the 'Prehospital Ambulance 12-lead Electrocardiogram for Chest Pain Patients in Hong Kong West Cluster' pilot project (12 November 2015 to 5 November 2017). Data were provided by the QMH AED, QMH Cardiac Care Unit (CCU), and HKFSD.

The QMH CCU provided the list of all patients admitted through the AED with emergency

\section{院前心電圖縮短罹患ST上升心肌梗塞病人的 心肌缺血時間}

張健碩、梁令邦、蕭粵中、曾達之、徐錫漢、譚礎璋、陳漢鏵

引言 : 在處理罹患ST上升心肌梗塞 (STEMI) 的病人時, 應該盡可能 縮短心肌總缺血時間。本研究檢視院前 12 導心電圖能否縮短STEMI處 理的系統性阻延。

方法：2015年11月至2017年11月期間, 在 15 部瑪麗醫院服務範圍內 的救護車上配置了 $X$ 系列去顫器 / 監護儀, 為胸痛病人進行院前 12 導 心電圖並傳送到急症室供醫生即時分析。本研究比較三組STEMI病人 的數據, 分別為院前心電圖上顯示有ST上升、乘坐救護車而沒有進行 院前心電圖, 以及自行安排交通工具前往醫院的病人。

結果：對197名罹患STEMI病人數據進行分析。病人自身阻延時間 的中位數為 90 分鐘； $12 \%$ 病人的自身阻延時間超過 12 小時。乘坐 救護車和自行安排交通工具兩組病人的自身阻延時間有顯著差異 $(\mathrm{P}<0.001)$ 。系統性阻延方面, 院前心電圖可縮短由救護員到場 至首張心電圖的中位數時間 $(\mathrm{P}<0.001)$ 。另外, 在現場即時進行 比在救護車上進行院前心電圖早5分鐘有結果。院前心電圖的應用 可縮短病人的急症室登記到分流時間、急症室登記至首張心電圖時 間、急症室登記至診症時間, 以及在急症室逗留時間（以上各項皆為 $\mathrm{P}<0.001$ )

結論：院前心電圖能縮短入院前的心肌缺血時間。

coronary angiography, with or without PPCI. This included patients who travelled to hospital by selfarranged transport, as well as those who travelled by ambulance with and without prehospital 12-lead ECG. Patients were excluded if they had STEMI that developed during in-patient stay, if they had post-arrest malignant arrhythmia, or if they had extracorporeal-membrane-oxygenation-assisted cardiopulmonary resuscitation (ECMO-CPR). Patients secondarily transported from St John Hospital on an outlying island were also excluded. The HKFSD and QMH AED provided data regarding the first and second phases of our pilot project, in which 15 HKFSD ambulances in Hong Kong West Cluster were equipped with X Series Defibrillator/ Monitor (Zoll Medical Corporation, Chelmsford [MA], US). Prehospital 12-lead ECGs of chest pain patients were tele-transmitted to the AED for immediate assessment by an emergency physician. Physicians from $\mathrm{CCU}$ received alerts regarding patients with suspected STEMI in ECG. This pilot project began on 12 November 2015; the first phase ended on 31 December 2016. In the first phase, all prehospital ECGs were obtained in ambulance compartments before departure from the scene. In the second phase (1 January 2017 to 5 November 2017), prehospital ECGs were performed either upon ambulance on scene or in the ambulance compartment, as determined by the ambulance 
crew based on the feasibility of carrying the X Series Defibrillation/Monitor to the scene.

The primary objective of this study was to investigate whether there were significant differences in patient and system delays between the use of prehospital 12-lead ECG and standard care. The primary outcomes were the patient and system delay times in minutes. Patient delay was measured from the time of symptom onset to the time of emergency response system activation. The times of emergency response system activation were the time of the 999 call for ambulance patients and the time of AED registration for patients with self-arranged transport. System delay was measured from the time of emergency response system activation to the time of admission through the AED. System delay was further stratified as the time from ambulance on scene to AED registration; ambulance on scene to first ECG (for patients travelling by ambulance); AED door-to-triage time, AED door-to-first AED ECG time, AED door-to-physician consultation time, and length of stay in the AED (for all patients). The secondary objective of this study was to assess accuracy of triage, benefit of performing prehospital ECG when ambulance on scene compared with in the ambulance compartment, ability to call CCU on/before patient arrival, and adherence to HKFSD performance pledge. Triage accuracy was measured by proportion of patients correctly triaged as category 1. Benefit of performing prehospital ECG when ambulance on scene compared with in the ambulance compartment was measured by shortened time in minutes to undergo ECG when the former is performed. Ability to call CCU on/before patient arrival was measured by the proportion of patients with CCU calls on/before AED registration. Adherence to HKFSD performance pledge was measured as the time from 999 call to the time of ambulance arrival at the street address.

Data were analysed by Excel 2010 (Microsoft Corp, Redmond [WA], US) and SPSS (Windows version 25.0; IBM Corp, Armonk [NY], US). The non-parametric Mann-Whitney $U$ test was used to analyse statistical differences between groups.

\section{Results}

In all, 245 patients were admitted through the AED to the CCU with emergent coronary angiogram, with or without PPCI. In total, 43 patients were excluded because they developed STEMI during in-patient stay, exhibited post-arrest malignant arrhythmia, or required ECMO-CPR. In addition, five patients who were secondarily transported from St John Hospital were excluded. Data were analysed for a total of 197 patients from CCU and our pilot project. In the first phase, 118 patients were included; all underwent prehospital ECGs in the ambulance compartment. In the second phase, 79 patients were included; 36 and eight underwent prehospital ECGs in the ambulance compartment and on scene, respectively. The remaining 35 patients were transported by ambulances without prehospital ECG capabilities (Fig).

\section{Patient delay}

The median patient delay time was 90 minutes; $12 \%$ of patients experienced delays of $>12$ hours. There was significant difference in patient delay between patients travelling by ambulance and those who used self-arranged transport (Table 1).

\section{System delay}

There were significant differences between patients with and without prehospital ECG, in terms of median time from ambulance on scene to AED registration (Table 2), and ambulance on scene to first ECG (Table 3). Prehospital ECG was available 5 minutes earlier if performed upon ambulance 
TABLE I. Patient delay (time of symptom onset to time of activating emergency response system)

\begin{tabular}{|c|c|c|c|c|c|c|}
\hline \multirow[b]{2}{*}{ All patients with STEMI $(n=197)$} & \multirow{2}{*}{$\begin{array}{c}\begin{array}{c}\text { Excluded patients } \\
\text { (unknown symptom } \\
\text { onset or call 999 time) }\end{array} \\
6\end{array}$} & \multirow{2}{*}{$\begin{array}{c}\begin{array}{c}\text { Included } \\
\text { patients }\end{array} \\
191(97 \%)\end{array}$} & \multicolumn{2}{|c|}{$\begin{array}{l}\text { Delay, median (interquartile } \\
\text { range), min }\end{array}$} & \multicolumn{2}{|c|}{$\begin{array}{c}\text { Patients with }>12 \text {-h delay } \\
\text { No. }(\%)\end{array}$} \\
\hline & & & $90(30-318)$ & - & $23 / 191(12 \%)$ & - \\
\hline Travel by ambulance $(n=129)$ & 5 & 124 (96\%) & $46(18-156)$ & \multirow{2}{*}{$\mathrm{P}<0.001^{*}$} & $11 / 124(9 \%)$ & \multirow{2}{*}{$\mathrm{P}<0.001^{\star}$} \\
\hline Self-arranged transport $(n=68)$ & 1 & 67 (99\%) & $211(106-599)$ & & $12 / 67(18 \%)$ & \\
\hline
\end{tabular}

Abbreviation: STEMI = ST-segment elevation myocardial infarction

* Non-parametric Mann-Whitney $U$ test

on scene compared with that in ambulance compartment. This 5-minute difference also gave us an estimate of time required to transfer the patient to the ambulance from the scene where the patient experienced chest pain. Prehospital ECG performed at the time of ambulance on scene was available 35 minutes earlier than the first ECG (in the AED) for patients who used self-arranged transport.

After excluding six patients with unknown time of 999 call or unknown time of ambulance arrival on scene, the median time from 999 call to ambulance on scene was 8 minutes (interquartile range, 6-10 minutes). Overall, 119 of 123 (96.7\%) patients had times within 17 minutes (12 minutes to street address performance pledge by HKFSD, plus 5 minutes travel time between ambulance and scene). Forty-three patients with STEMI underwent prehospital ECG and had known CCU call times; of these, ambulance crews in 7 of 8 with ECG performed on scene (88\%), and 25 of 35 with ECG performed in the ambulance compartment $(71 \%)$, were able to contact the $\mathrm{CCU}$ physician on or before patient arrival in AED. With prehospital ECG, AED door-to-triage time, AED door-to-first AED ECG time, AED door-to-physician consultation time, and length of stay in the AED were all significantly shortened. In addition, more patients with STEMI were correctly triaged as category 1 if they had undergone prehospital ECG (Table 4).

\section{Discussion}

\section{Patient delay}

The MEDEA study showed that female sex and age $>65$ years were factors associated with delayed presentation in patients with acute myocardial infarction. ${ }^{4}$ Perceived barriers in care-seeking and symptom congruence were also associated with prehospital delays in Hong Kong Chinese patients with acute myocardial infarction. ${ }^{5}$ Although current guidelines recommend PPCI by an experienced team within 12 hours of symptom onset as a reperfusion strategy in patients with STEMI, ${ }^{2} 12 \%$ of patients in our study called 999 or arrived at the AED $>12$ hours after symptom onset (Table 1). These delays might have worsened their outcomes. Moreover, 15
TABLE 2. Ambulance on scene to Accident and Emergency Department registration time

\begin{tabular}{lc}
\hline & $\begin{array}{c}\text { Median ambulance on scene } \\
\text { to AED registration time } \\
\text { (interquartile range), min }\end{array}$ \\
\hline $\begin{array}{l}\text { All }(\mathrm{n}=129) \text { ambulance transported patients } \\
(1 \text { unknown scene time), } \mathrm{n}=128\end{array}$ & $27(23-31)$ \\
$\begin{array}{l}\text { With prehospital ECG, } \mathrm{n}=44 \\
\text { Without prehospital ECG, } \mathrm{n}=84\end{array}$ & $25(22-29)$ \\
\hline
\end{tabular}

Abbreviations: AED = Accident and Emergency Department; ECG = electrocardiogram * Non-parametric Mann-Whitney $U$ test

TABLE 3. Ambulance on scene to first electrocardiogram time $(n=128)$

\begin{tabular}{|c|c|c|}
\hline & $\begin{array}{l}\text { Median } \\
\text { ambulance } \\
\text { on scene to } \\
\text { first ECG time } \\
\text { (interquartile } \\
\text { range), min }\end{array}$ & P value* \\
\hline With prehospital ECG $(n=44)$ & $10(7-14)$ & $<0.001$ \\
\hline First ECG on scene $(n=8)$ & $6(5-7)$ & \\
\hline $\begin{array}{l}\text { First ECG in ambulance compartment } \\
(n=36)\end{array}$ & $11(8-14)$ & \\
\hline $\begin{array}{l}\text { Without prehospital ECG (first ECG in AED, } \\
n=84 \text { ) }\end{array}$ & $41(33-51)$ & $\begin{array}{l}<0.001 \text { (vs with } \\
\text { prehospital ECG) }\end{array}$ \\
\hline
\end{tabular}

Abbreviations: AED = Accident and Emergency Department; ECG = electrocardiogram * Non-parametric Mann-Whitney $U$ test

of 197 (7.6\%) were evaluated by another physician before they presented to the AED, and those other physicians might have performed ECG in their clinics. Regardless of the availability of ECG in the other clinics, there is no formal communication channel between the AED and private physicians, with the exception of referral letters. These factors may also have contributed to delays.

A key factor for reducing prehospital delay is education of the public, especially high-risk patients, regarding the prudent use of emergency medical services and the typical symptoms of myocardial infarction. Online symptom checkers have been devised for patient self-diagnosis. However, an audit study found only moderate accuracy in 
TABLE 4. Accident and Emergency Department door-to-triage time, door-to-first AED ECG time, door-to-physician consultation time, correct triage category, and length of stay in the AED*

\begin{tabular}{|c|c|c|c|c|}
\hline & \multirow{2}{*}{$\begin{array}{c}\text { With ECG in } \\
\text { ambulance }(n=44)\end{array}$} & \multicolumn{2}{|c|}{ Without ECG (n=153) } & \multirow[t]{2}{*}{$\mathbf{P}$ value } \\
\hline & & $\begin{array}{l}\text { Ambulance without } \\
\text { ECG }(n=85)\end{array}$ & $\begin{array}{l}\text { Self-arranged } \\
\text { transport }(n=68)\end{array}$ & \\
\hline \multirow[t]{2}{*}{ Door-to-triage } & $0(0-1)$ & \multicolumn{2}{|c|}{$2(0-4)$} & $P<0.001 \ddagger$ \\
\hline & & $2(0-4)$ & $2(0-5)$ & - \\
\hline \multirow[t]{2}{*}{ Correctly triaged as category 1} & $40(91 \%)$ & \multicolumn{2}{|c|}{$87(57 \%)$} & $P<0.001 \mp$ \\
\hline & & $44(52 \%)$ & $43(63 \%)$ & - \\
\hline \multirow[t]{2}{*}{ Door-to-first AED ECG time } & $\mathrm{n}=43 \dagger, 6(4-7)$ & \multicolumn{2}{|c|}{$\mathrm{n}=152,12(7-19)$} & $P<0.001 \ddagger$ \\
\hline & & $\mathrm{n}=84 \dagger, 11(5-18)$ & $14(10-21)$ & - \\
\hline \multirow[t]{2}{*}{ Door-to-physician consultation time } & $0(0-1)$ & \multicolumn{2}{|c|}{$5(0-19)$} & $P<0.001 \mp$ \\
\hline & & $6(0-16)$ & $4(0-25)$ & - \\
\hline \multirow[t]{2}{*}{ Length of stay in the AED } & $29(22-37)$ & \multicolumn{2}{|c|}{$58(42-75)$} & $P<0.001 \mp$ \\
\hline & & $54(38-72)$ & $60(46-82)$ & - \\
\hline
\end{tabular}

Abbreviations: AED = Accident and Emergency Department; ECG = electrocardiogram

* Data are shown as median time (interquartile range) in minutes, unless otherwise specified

t I patient with unknown AED ECG time

$\ddagger$ Non-parametric Mann-Whitney $U$ test

these algorithms. ${ }^{6}$ Because patients with STEMI often have other medical co-morbidities that require regular follow-up by family physicians or general out-patient clinics, education regarding typical symptoms of myocardial infarction and the availability of prehospital ECG assessments could be provided during these regular consultations. Notably, prehospital ECG can be performed only after a patient has activated the emergency response system; therefore, it cannot shorten the patient delay unless it is coupled with public education regarding STEMI symptoms and public awareness of prehospital ECG availability.

\section{Self-arranged travel versus ambulance transport}

Approximately one-third of patients with STEMI in our pilot project used self-arranged transport for travelling to the hospital. This phenomenon is not unique to Hong Kong. ${ }^{7-9}$ Compared with patients travelling by ambulance, a greater proportion of patients travelling by self-arranged transport had patient delay time of $>12$ hours (Table 1 ). Self-arranged transport patients did not undergo prehospital ECG. The delayed activation of the emergency response system deprived such patients of early assessment by an ambulance crew, as well as early notifications to the AED and CCU physicians of unstable vitals and a potential need for life-saving treatment. It is important to educate the public on appropriate use of ambulance services. Mass media campaigns regarding use of ambulances for chest pain have been shown to increase emergency medical system use by people with chest pain and suspected acute coronary syndromes. ${ }^{10}$ In this study, there was a significant difference in the median times for ambulance patients to make 999 calls and for self-arranged transport patients to register in the AED (Table 1). This may be related to differences in awareness of STEMI symptoms, different patient attitudes regarding management of their own symptoms, and different treatment expectations regarding ambulance services. Education should emphasise early 999 calls for patients with STEMI symptoms, instead of the use of self-arranged transport.

\section{The Hong Kong Fire Services Department performance pledge}

For emergency ambulance calls, the HKFSD has a performance pledge of within 12 minutes for $92.5 \%$ of patients, from the time of the call to the arrival of an ambulance at the designated street address. ${ }^{11}$ For chest pain patients with suspected myocardial infarction, even when 5 additional minutes are added to include travel time from the ambulance to the scene (as estimated in Table 3), this pledge remains more stringent than those of ambulance services in other countries. For example, the average response time by the London Ambulance Service for corresponding category 2 calls is 18 minutes. ${ }^{12}$ In our 123 patients with STEMI who were transported by ambulances, the median response time was 8 minutes; $96.7 \%$ of patients received a response within the target of within 17 minutes during the pilot project. By enhancing the mobilising system 
and commissioning new fire stations/ambulance depots at various locations, the response time for chest pain patients is expected to decrease further.

\section{Prehospital electrocardiogram and the potential for delayed transport to the hospital}

Before this pilot project was implemented, there were concerns regarding delayed transport to the hospital due to the performance of prehospital ECG. In contrast to our expectations, the median sceneto-AED registration time was 3 minutes shorter in patients who underwent prehospital ECG, compared with patients who did not undergo prehospital ECG (Table 2). However, every ambulance journey was unique and involved a different travel distance. Because the actual distances travelled and the proportions of time used for performing prehospital ECG in each ambulance journey were not available, a larger data analysis is needed to clarify these findings.

\section{On scene or in ambulance compartment}

Among the 44 patients with STEMI who underwent prehospital ECG, the CCU physician was called before patient arrival in 7 of 8 (88\%) patients for whom ECG was performed on scene and in 25 of 35 (71\%) patients for whom ECG was performed in the ambulance compartment. The CCU call time was unknown for the remaining one patient. Therefore, performing prehospital ECG on scene allowed earlier CCU consultations. It has been recommended that 12-lead ECG recording and interpretation should be performed as soon as possible upon initial medical contact, with a target maximum delay of 10 minutes..$^{13}$ This target was achieved in our pilot project in patients for whom prehospital ECG was performed on scene (median time: 6 minutes) [Table 3]. We were near this target in patients for whom ECG was performed in the ambulance compartment (median time: 11 minutes). Therefore, ECG performance on scene, rather than in the ambulance compartment, is recommended whenever feasible.

\section{More efficient Accident and Emergency Department management in multiple steps}

Preliminary history and vital signs collected during ambulance transport were immediately given to the triage nurse upon patient arrival. This shortened the triage time to 0 minutes (door-to-triage time) in patients for whom prehospital ECG was performed. Moreover, triage accuracy was improved: more patients with STEMI (40/44) who underwent prehospital ECGs were correctly triaged as category 1 (critical) and therefore received immediate treatment. Shortened times for door-to-first AED ECG and door-to-consultation were evident. Patients with STEMI who were transported by ambulance could provide notification to the AED before their arrival, thereby enabling pre-arrival preparation of an acute care room. In addition, an immediate AED physician assessment with repeat ECG could be performed upon patient arrival. These changes resulted in an overall reduction in the length of AED stay (nearly by half), compared with the length of AED stay for patients who did not undergo prehospital ECG. Shortened length of AED stay is beneficial for percutaneous coronary intervention centres where patients with STEMI cannot yet bypass the AED with direct catheterisation laboratory admission.

\section{Conclusion}

Delayed activation of the emergency response system and choice of transportation contributed to patient delay. Prehospital 12-lead ECG, preferably performed on scene, can shorten system delay and total ischaemic time in STEMI management.

\section{Author contributions}

All authors had full access to the data, contributed to the study, approved the final version for publication, and take responsibility for its accuracy and integrity.

Concept or design: All authors.

Acquisition of data: KS Cheung, YC Siu, RHW Chan. Analysis or interpretation of data: KS Cheung, LP Leung. Drafting of the article: KS Cheung.

Critical revision for important intellectual content: All authors.

\section{Conflicts of interest}

All authors have disclosed no conflicts of interest.

\section{Acknowledgement}

We would like to thank the staff of the following institutions: (1) Hong Kong Fire Services Department, for performing prehospital electrocardiograms and providing prehospital data; (2) Division of Cardiology, Department of Medicine, Queen Mary Hospital, for providing data on door-to-balloon and door-to-catheter time; (3) Department of Accident and Emergency, Queen Mary Hospital, for collecting patient clinical data; (4) Mr Fan Min of Emergency Medicine Unit, Li Ka Shing Faculty of Medicine, The University of Hong Kong, for statistical analyses; and (5) Zoll Medical Corporation (Chelmsford [MA], US), for providing the machines, training, and technical support free of charge.

\section{Funding/support}

This research received no specific grant from any funding agency in the public, commercial, or not-for-profit sectors.

\section{Ethics approval}

Analysis of data from this pilot project was approved by the Institutional Review Board of The University of Hong Kong/ Hospital Authority Hong Kong West Cluster (UW19-184). The requirement for patient consent was waived. 


\section{References}

1. HealthyHK, Department of Health, Hong Kong SAR Government. Coronary heart diseases. Available from: https://www.healthyhk.gov.hk/phisweb/en/healthy_facts/ disease_burden/major_causes_death/coronary_heart disease/. Accessed 21 Apr 2019.

2. Ibanez B, James S, Agewall S, et al. 2017 ESC Guidelines for the management of acute myocardial infarction in patients presenting with ST-segment elevation: The Task Force for the management of acute myocardial infarction in patients presenting with ST-segment elevation of the European Society of Cardiology (ESC). Eur Heart J 2018;39:119-77.

3. Cheung KS, Leung LP, Siu YC, et al. Prehospital 12-lead electrocardiogram for patients with chest pain: a pilot study. Hong Kong Med J 2018;24:484-91.

4. Ladwig KH, Fang X, Wolf K, et al. Comparison of delay times between symptom onset of an acute ST-elevation myocardial infarction and hospital arrival in men and women $<65$ years versus $\geq 65$ years of age: findings from the Multicenter Munich Examination of Delay in Patients Experiencing Acute Myocardial Infarction (MEDEA) Study. Am J Cardiol 2017;120:2128-34.

5. Li PW, Yu DS. Predictors of pre-hospital delay in Hong Kong Chinese patients with acute myocardial infarction. Eur J Cardiovasc Nurs 2018;17:75-84.

6. Semigran HL, Linder JA, Gidengil C, Mehrotra A. Evaluation of symptom checkers for self diagnosis and triage: audit study. BMJ 2015;351:h3480.

7. Hong CC, Sultana P, Wong AS, Chan KP, Pek PP, Ong
ME. Prehospital delay in patients presenting with acute ST-elevation myocardial infarction. Eur J Emerg Med 2011;18:268-71.

8. Mathews R, Peterson ED, Li S, et al. Use of emergency medical service transport among patients with STsegment-elevation myocardial infarction: findings from the National Cardiovascular Data Registry Acute Coronary Treatment Intervention Outcomes Network Registry-Get with the Guidelines. Circulation 2011;124:154-63.

9. Lavery T, Greenslade JH, Parsonage WA, et al. Factors influencing choice of pre-hospital transportation of patients with potential acute coronary syndrome: an observational study. Emerg Med Australas 2017;29:210-6.

10. Nehme Z, Cameron PA, Akram M, et al. Effect of a mass media campaign on ambulance use for chest pain. Med J Aust 2017;206:30-5.

11. Fire Services Department, Hong Kong SAR Government. Performance pledge. Available from: https://www.hkfsd. gov.hk/eng/aboutus/performance.html. Accessed 21 Apr 2019.

12. NHS London Ambulance Service. New ambulance response categories. Available from: https://www. londonambulance.nhs.uk/calling-us/17086-2/. Accessed 21 Apr 2019.

13. Diercks DB, Peacock WF, Hiestand BC, et al. Frequency and consequences of recording an electrocardiogram $>10$ minutes after arrival in an emergency room in non-STsegment elevation acute coronary syndromes (from the CRUSADE Initiative). Am J Cardiol 2006;97:437-42. 